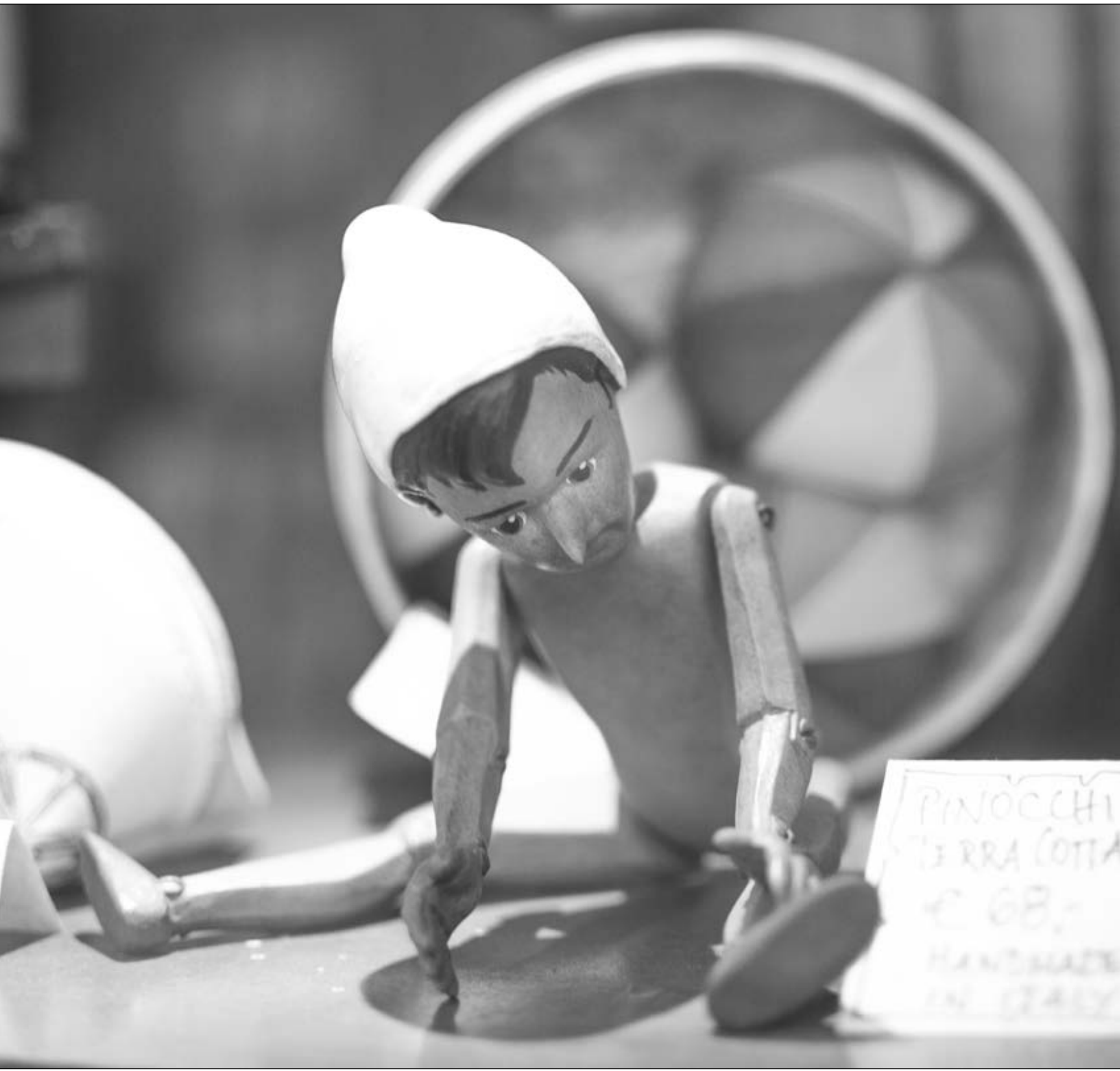




\title{
Imagem, Retórica e História da Arte em Pinóquio, de Walt Disney Pictures
}

\author{
Imagen, Retórica e Historia del Arte en Pinocho, \\ de Walt Disney Pictures
}

\section{Image, Rhetoric and History of Art in Walt Disney Pictures' Pinocchio}

DOI: https://doi.org/10.22235/d.v0i29.1698

Luis Fernando Beloto Cabral y Yanet Aguilera

RESUMO

0 texto propõe uma reflexão sobre os filmes de animação dos estúdios Disney, a partir da análise do longa-metragem Pinóquio (Pinocchio), originalmente lançado em 1940 e dirigido por Ben Sharpsteen e Hamilton Luske. 0 artigo orienta-se principalmente pela leitura das imagens do filme, com o objetivo de interpretar o estilo gráfico dos desenhos da Disney e os repertórios iconográficos e imagéticos referenciados pelas animações. 0 texto termina com uma reflexão sobre a relação dos desenhos da Disney com a tradição narrativa hollywoodiana e seu efetivo valor como produção de caricaturas e encenações.

Palavras-chave: Pinóquio; Walt Disney Pictures; cinema de animação; análise fílmica; história da arte.

\section{RESUMEN}

El texto propone una reflexión sobre el cine de animación de los estudios Disney a partir del análisis del largometraje Pinocho (Pinocchio), lanzado originalmente en 1940 y dirigido por Ben Sharpsteen y Hamilton Luske. El artículo se orienta principalmente por una lectura de las imágenes de la película, con el objetivo de interpretar el estilo gráfico de los dibujos Disney y los repertorios iconográficos y de composición imagética referenciados por las animaciones. El texto se cierra con una reflexión sobre la relación de los dibujos Disney con la tradición narrativa hollywoodiana y su efectivo valor como producción de caricaturas y escenarios. Palabras clave: Pinocho; Walt Disney Pictures; cine de animación; análisis filmico; historia del arte.

\section{ABSTRACT}

The text proposes a reflection on the animated films of Disney studios based on the analysis of the feature film Pinocchio, originally released in 1940 and directed by Ben Sharpsteen and Hamilton Luske. The article is mainly oriented by a reading of the images of the film, with the aim of interpreting the graphic style of the Disney drawings and the iconographic and imaginative repertoires referenced by the animations. The text closes with a reflection on the relationship of the Disney drawings with the Hollywood narrative tradition and its effective value as a production of cartoons and staging.

Keywords: Pinocchio; Walt Disney Pictures; animation film; film analysis; history of art. 
Luis Fernando Beloto Cabral ORCID: 0000-00022122-2193

Universidade Federal de São Paulo, Guarulhos, Brasil Correspondencia: Ifbelotocabral@gmail.com

Yanet Aguilera ORCID: 0000-00020801-5472

Universidade Federal de São Paulo, Guarulhos, Brasil Correspondencia: keyichinita@gmail.com

Recepción: 14/04/2018 Aceptación: 21/09/2018

1:: Artigo derivado da pesquisa Técnica e Estética:

A llusão da Vida em Pinóquio, de Walt Disney Pictures, financiada pela Fundação de Amparo à Pesquisa do Estado de São Paulo (FAPESP).

\section{Introdução}

Há uma cena de Pinóquio (Pinocchio, 1940) em que o protagonista, decidido a ir à escola e seguir o bom caminho, diz "I'd rather be smart than an actor" -na dublagem em português do Brasil, "quero ser inteligente, não artista”. Mesmo sem a intenção, a fala é de uma enorme ironia se considerarmos o conjunto do filme: além do forte apelo plástico e pictórico da cenografia, a animação apresenta uma série de números musicais e de comédia, ao modo de um espetáculo vaudeville misturado com um filme hollywoodiano.

Alguns números, inclusive, são estrelados pelos próprios "mocinhos" da história, em especial o Grilo Falante que é a consciência do boneco de pinho. Essa é uma das contradições que perpassam o longa-metragem, o qual igualmente povoado de figuras grotescas e soturnas que desafiam a moral agridoce da narrativa.

É a partir destas contradições (perceptíveis sobretudo nas primeiras animações do estúdio) que o presente texto $^{1}$ deseja abordar a animação Disney, buscando um outro caminho que não é o da crítica usual exclusivamente voltada aos valores ideológicos da corporação Disney, embora estes indubitavelmente não possam ser ignorados.

\section{A retórica do iconoclasmo}

e a mercadoria como arte

Em Iconology: Image, Text, Ideology, W. J. T. Mitchell (1987) expõe a iconoclastia da tradição ocidental que sempre desvalorizou as imagens em relação ao texto -e um exemplo deste menosprezo é o fato dos estudiosos das letras desconsiderarem que as palavras evocam imagens. Entretanto, como é impossível se expressar sem imagens, os iconoclastas estabelecem uma luta pelo poder que visa destruir as imagens do outro para o culto exclusivo das suas (Mitchell, 1987). E ainda segundo Mitchell, a iconoclastia atinge não apenas os ídolos e seus patronos, mas os "idólatras":
Insofar as the stress is on the folly of the idolater, he is an object of pity who requires education and therapeutic conversion "for his own good".... The idolater is, by definition, subhuman and until it is shown that he can be educated into full humanity, he is a fit object for religious persecution, exile from the community of believers, enslavement, or liquidation (p. 197-198).

Podemos associar a retórica iconoclasta à crítica que se fez à indústria cultural. A desconstrução das ilusões da mídia e a condenação dos produtos da cultura de massa integraram uma missão messiânica de combate às imagens do capitalismo. No âmbito acadêmico e na teoria cinematográfica essa iconoclastia atingiu os desenhos Disney. As animações são repudiadas pelo conteúdo ideológico de suas narrativas, para não mencionar o descaso com os filmes de temática infanto-juvenil. Os numerosos produtos licenciados, o espetáculo dos parques temáticos e a onipresença nas ações do mercado cinematográfico, midiático e fonográfico igualmente reforçam a resistência aos produtos do estúdio/corporação.

Não é nosso objetivo diminuir ou negar as críticas ao conservadorismo de Walt Disney. Mas como vimos, a condenação dos ídolos pressupõe a igual condenação dos "idólatras", e desse modo, a crítica à cultura de massa, à qual são associados os filmes Disney, pode produzir um julgamento moral sobre aqueles e aquelas que consomem os produtos dessa mídia -o que perpetua relações paternalistas conservadoras. Tal crítica tende a subestimar a capacidade dos espectadores em se colocar ativamente em relação ao que veem e escutam, como Jacques Rancière (2012) nos mostra em $O$ espectador emancipado:

0 que permite declarar inativo o espectador que está sentado em seu lugar, senão a oposição radical, previamente suposta, entre ativo e passivo? Por que identificar olhar e passividade, senão pelo pressuposto de que olhar quer dizer comprazer-se 
com a imagem e com a aparência, ignorando a verdade que está por trás da imagem e a realidade fora do teatro?.... 0 espectador também age, tal como o aluno ou o intelectual. Ele observa, seleciona, compara, interpreta.... são ao mesmo tempo espectadores distantes e intérpretes ativos do espetáculo que lhes é proposto (p.16-17).

A rejeição às imagens da "sociedade do espetáculo" também nos deixa vulneráveis a instâncias de poder e mercado que não só entendem de imagem como sabem utilizá-la para seus interesses comerciais e políticos, e a corporação Disney é talvez um dos melhores exemplos disso. A crítica de Mitchell dirige-se à ilusão de que é possivel nos situarmos em uma instância superior do conhecimento, fora de qualquer ideologia. 0 que o autor defende é não tanto uma condenação dos iconoclastas, mas um exercício constante de autocrítica que presume até a revisão de conceitos e terminologias colocados em uma zona de neutralidade. A autocrítica convida-nos a rever nossa própria relação com os desenhos Disney. A reavaliação, positiva ou negativa, dos filmes não deve descartar o fato de que estes pertencem a uma memória afetiva, compartilhada por todos que assistiam aos desenhos no cinema ou no vídeo. ${ }^{2}$ Não vivemos fora da cultura de massa. Também consumimos a indústria cultural e também construímos com estes e outros filmes afetos e memórias que envolvem uma experiência lúdica.

A elaboração técnica e o vasto repertório iconográfico, usualmente subestimados e expostos neste artigo, são o diferencial da animação Disney e seu principal chamariz, e nisso a relação dos filmes com a história da arte vai muito além do kitsch. Mitchell (1987) propõe que a afınidade entre uma obra de arte e a mercadoria é muito maior do que gostaríamos de imaginar. Segundo o autor, na crítica estética marxista, posterior a Marx, a obra de arte sempre foi avaliada junto ao conceito de ideologia em detrimento do conceito de fetiche, apesar deste ser o mais proeminente na obra derradeira de Marx e possuir um vínculo direto com a produção artística (por exemplo, a incorporação do fetiche, nas sociedades tribais, em estatuetas ou outras peças de arte). Para Mitchell, o fetichismo foi rejeitado por simbolizar uma forma degradada de comportamento à qual jamais se pensou associar o objeto sublime e espiritualizado da arte. 0 fetichismo também referencia o mundo das coisas em sua materialidade, e seu vínculo com a arte relegaria a última ao status indesejado de objeto (Mitchell, 1987).

Mas sendo a mercadoria, no pensamento original de Marx, um objeto personalizado imbuído de forte investimento simbólico, ou "um produto social equiparável à linguagem”, ela não seria portanto algo tão diferente de uma obra de arte: "Before we dismiss the "vulgar" notion of art as a commodity, therefore, we need to contemplate the refinements of Marx's claim that a commodity is something very like a work of art." (Mitchell,1987, p.188). É claro que a provocação não nivela as imagens da indústria cultural com as de Velásquez ou Degas, mas o que Mitchell parece dizer é que, apesar dos diferentes contextos, tanto na arte quanto na mercadoria tem-se a projeção de uma consciência e de um pathos sobre um objeto material que é elevado a outro status, incluindo o de adoração. E assim como várias obras e artistas tornaram-se fetiches da história da arte, a mercadoria, em graus variados, não é tratada como um penduricalho qualquer do mercado.

Seria então absurda a ideia de uma afınidade ou interação entre a indústria cultural e a produção canônica de arte? Esses dois polos, maniqueistamente separados em boa e má arte, ou em bom e mau gosto, não estariam profundamente imbricados? Nesse sentido, a análise das animações Disney é estratégica porque os filmes do estúdio talvez sejam os que mais explicitamente colocam a relação entre cânone e indústria, considerando a produção literal de imagens que bebem de todo um repertório das artes plásticas. A história da arte e o cinema experimental podem ser considerados inclusive não uma
2:: É o que se supõe pelo menos da ampla distribuição dos filmes Disney no mercado global, como demonstra os registros de bilheteria compilados no site Box Office Mojo -no 2018, por exemplo três dos cinco títulos mais lucrativos foram distribuídos pelos estúdios Disney (Box Office Mojo, 2018)-, e isso sem mencionar a exibição dos filmes em canais de televisão e os lançamentos em Home Vídeo. Os estúdios Disney como referência cultural é também evidente nas citações feitas por diversas mídias e manifestações de arte, de grafites anônimos aos de nome mais consagrados como Bansky a filmes com outras propostas de animação, como Allegro non Troppo (1976), de Bruno Bozzeto, o qual é uma sátira ao filme Fantasia (1940). 
3:: Na monografia Cinema de Animação no Brasil-História e Indústria Moderna, o animador Marco Antônio Souza de Athaide defende a produção experimental de animação, justamente com o argumento de que esta beneficiaria a indústria nacional, ainda incipiente, por desenvolver novas técnicas, conceitos e narrativas que enriqueceriam a produção brasileira. oposição a Hollywood, mas uma fonte de inspiração à mesma. A diversificação dos repertórios fílmicos dependeria da apropriação dessas outras narrativas e imagens, em uma dialética entre "homogeneidade/padronização" e "novidade/individuação" como apontado por Edgar Morin em seu Cultura de Massas no Século XX (2011) -e de fato, estúdios como Disney e Pixar investem até hoje na realização paralela de curtas-metragens que testam técnicas e conceitos promissores para os filmes de maior duração. ${ }^{3}$

Mitchell cogita se a estética não integraria a "névoa de familiaridade" que dissimula o caráter fetichista da mercadoria. A mistificação da própria arte, amparada sob os ideais de "beleza", "pureza” ou "expressividade espiritual”, ocultaria o lugar que as obras ocupam na ordem material e histórica (Mitchell, 1987). 0 valor agregado pela estética, derivado não apenas de um preciosismo formal, mas de processos retóricos de imagem, seria estratégico para a veneração dos objetos da arte e do mercado, ou, na lógica capitalista, para o retorno garantido aos seus produtores. Propomos estudar os desenhos Disney sob essa perspectiva e com base na análise de suas imagens, partindo do longa-metragem Pinóquio (Pinocchio, 1940), de Ben Sharpsteen e Hamilton Luske.

\section{Animação e História da Arte}

Apesar das narrativas conservadoras e simplificadas, as animações Disney apresentam uma produção elaborada de imagem que estabelece um diálogo com as artes eruditas e populares e as teorias da história da arte. Essa relação é perceptivel no que os filmes apresentam em sua confıguração final e é explicitada pelas descrições técnicas do livro The Illusion of Life (1981/1995), de Frank Thomas e Ollie Johnston, animadores veteranos do estúdio. Os artistas Disney empregavam um modo acadêmico de produção de imagens. Thomas e Johnston mencionam as aulas concedidas por Don Graham, instrutor da Chouinard's Art Institute, que, além do aprimoramento gráfico, promoviam estudos de anatomia e movimento com a análise de modelos vivos e filmes live-action. Os assistentes de animação, encarregados do refinamento das linhas do desenho, também eram versados em artistas como Hans Holbein, Edgar Degas, Honoré Daumier e Leonardo Da Vinci, e aos responsáveis pelos layouts (os sets e adereços de cena) eram recomendados conhecimentos em história da arte, arquitetura e vestuário. Alguns membros da equipe possuíam uma formação artística antes de ingressarem no estúdio, como os ilustradores Kay Nielsen e Gustaf Tengreen e o animador Vladimir 'Bill' Tytla (responsável, em Pinóquio, pela animação do cigano Stromboli). A riqueza iconográfica dos filmes advinha de um trabalho coletivo no qual cada animador com sua equipe encarregava-se de uma personagem, sem mencionar os grupos ocupados na concepção cenográfica, de câmera e musical (Thomas e Johnston, 1995).

Os animadores igualmente trabalhavam com um repertório popular de arte -mais especificamente, o desenho de caricatura, veiculado em jornais e periódicos. Segundo Thomas e Johnston (1995) Walt Disney preconizava que os desenhos deviam ser claros e objetivos, para que o público compreendesse rapidamente o propósito da cena. E apesar do estúdio ter sofisticado os seus símbolos visuais no decorrer dos anos, o desenho sintético do cartoon manteve-se como princípio norteador da composição imagética dos filmes. 0 desafıo dos desenhistas era justamente apresentar ideias e conceitos cada vez mais complexos de maneira ainda sucinta e direta (Thomas e Johnston, 1995). Além de profissionais formados, o estúdio recebeu artistas experientes em tirinhas de jornal, como Bill Cottrell e Joe Grant -o primeiro conhecido pela tirinha Krazy Kat, de George Herriman, e o segundo pelas caricaturas satíricas do Los Angeles Record. Eles eram aproveitados principalmente nos desenhos paródicos das animações, dentre outras figuras mais iconoclastas. É de Joe Grant, por exemplo, o design grotesco da Bruxa Má de Branca de Neve e os Sete Anões (Snow White and the Seven Dwarfs, 1937) (Allan, 1999). 


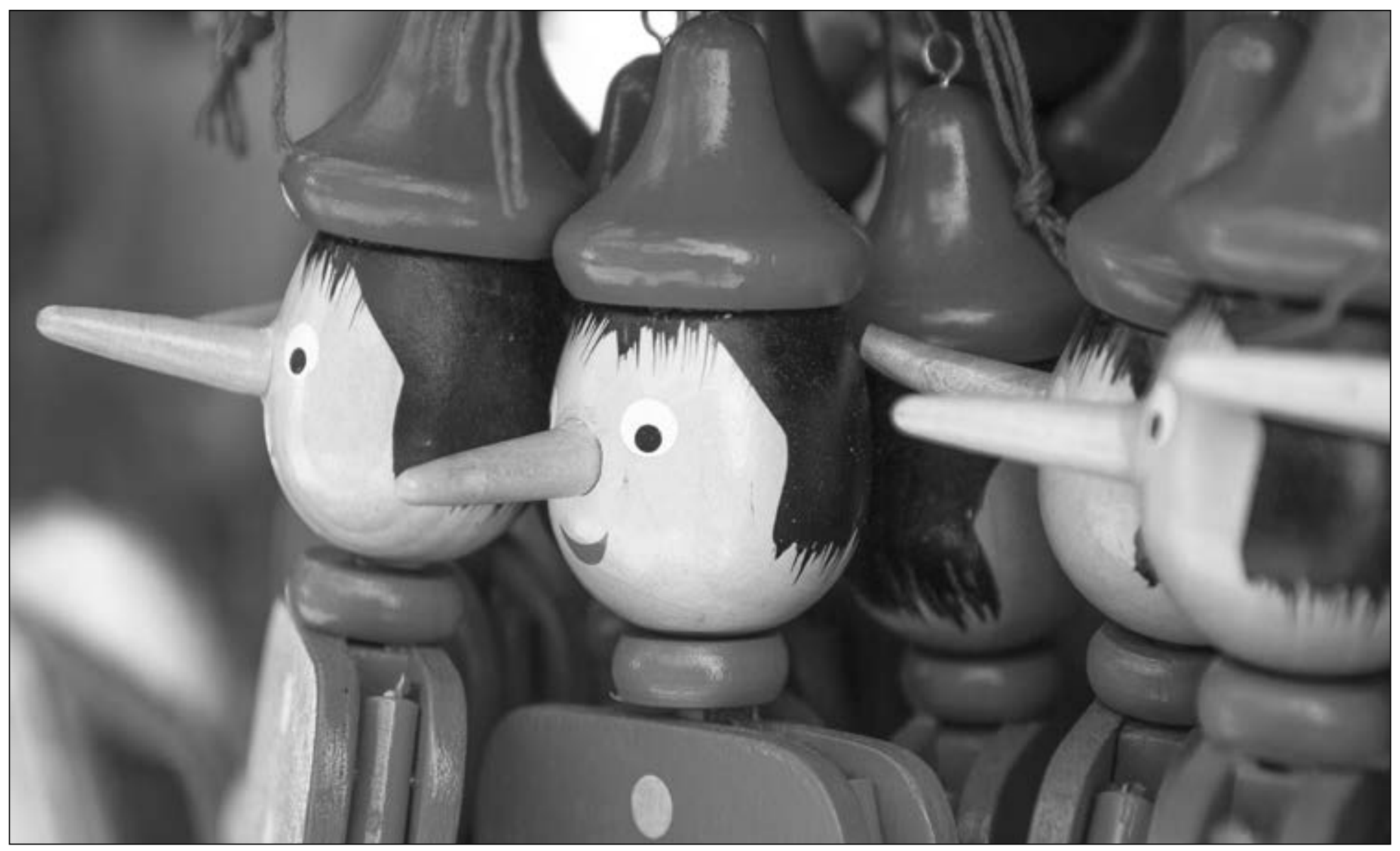

Embora The Illusion of Life apresente doze princípios para a animação Disney, ${ }^{4}$ dois deles são suficientes para entender o estilo gráfico do estúdio. 0 primeiro é o squash and stretch -em tradução livre, espremer e esticar- que consiste no achatamento e distensão dos traços e volumes do desenho. É ele que concede elasticidade e flexibilidade aos corpos da animação, exagerando as poses e expressões das personagens numa configuração mais caricata. A irreverência dos traçados e a maleabilidade dos corpos retomam as formas dinâmicas e engraçadas da caricatura de jornal e do próprio cartoon animado em suas origens. 0 segundo princípio, o do desenho sólido (solid drawing), aconselha que as personagens possuam peso, profundidade e equilíbrio. 0 ideal para os animadores Disney são o que eles chamam de corpos plásticos: corpos sólidos e tridimensionais, mas flexíveis o bastante para as demandas do squash and stretch. Os animadores mencionam a preocupação de Walt Disney com a anatomia das figuras. Em oposição aos corpos de borracha dos desenhos antigos, as personagens deviam, para Disney, apresentar ossos, músculo e gordura, mesmo com o formato engraçado de seus corpos de caricatura. A anatomia passou a influenciar os próprios movimentos do cartoon: se antes a personagem aumentava o comprimento do braço para pegar algum objeto distante, agora ela fazia um movimento complexo mobilizando todo o seu corpo, dado que a lógica corporal impede um alongamento tão excessivo (Thomas e Johnston,1995).

A caricatura é proeminente em Pinóquio, sobretudo em relação aos antagonistas e coadjuvantes cômicos, cujo desenho mais deformado acentua o caráter vilanesco ou humorístico. Ao analisar o filme, vemos que as caricaturas são destacadas na imagem por um tratamento distinto de linha e cor. Os desenhos em movimento diferenciam-se da composição cenográfica por apresentarem contornos pretos bem fortes e cores vibrantes e chapadas, enquanto que os elementos do entorno possuem traços difusos pictóricos e cores graduadas que emulam nuances de textura e iluminação. 0 desenho mais gráfico dos elementos animados remete às composições vibrantes
Foto: Pixabay

4:: Squash and Stretch, Anticipation, Staging, Straight Ahead Action and Pose to Pose,

Follow Through and Overlapping Action, Slow In and Slow Out, Arcs, Secondary Action, Timing, Exaggeration, Solid Drawing, Appeal. 
dos primeiros cartoons do estúdio, como os filmes de Mickey Mouse e as coloridas Silly Symphonies, dos anos 30. Há também um diálogo velado com o repertório de caricaturistas estadunidenses como W. W. Denslow, o qual praticamente antecipou a estética dos cartoons americanos, marcados pelo contorno gráfico forte (Allan, 1999). Denslow é conhecido por suas ilustrações para a primeira publicação de $O$ Mágico de $O z$, de Frank Baum.

As personagens Disney também apresentam corpos bastante tridimensionais. Em Pinóquio, o vilão Stromboli é muito volumoso. 0 desenho grotesco do cigano é agregado a um corpo robusto e pesado, definido pela grossura das pernas e braços e principalmente pela pança redonda destacada pela faixa vermelha da cintura. A animação ainda transmite uma forte sensação de peso e massa, sobretudo nos momentos mais assustadores em que Stromboli avança contra Pinóquio, impostando todo o seu corpo no cenário e fazendo-o tremer com o impacto. 0 desenho monumentaliza a personagem ao conceder-lhe um corpo escultórico de três dimensões e isso é potencializado pelos enquadramentos e posições da câmera -por exemplo, os planos próximos, em sutil câmera baixa, onde o que nos separa do cigano é apenas uma superfície de mesa, e os planos abertos com o vilão de corpo inteiro, necessários não para contextualizar a cena mas para comportar toda a corpulência dele.

0 mesmo acontece com outras personagens. Tanto em figuras pequenas como o gato Fígaro quanto em criaturas colossais como a baleia Monstro, vemos um corpo tridimensional complexo, dotado de peso, massa e anatomia. Isso é bastante evidente no desenho do protagonista, considerando o rosto esférico em formato de pera e as articulações de madeira nos braços e pernas. Os desenhos tridimensionais são valorizados pela câmera, nos enquadramentos em 45 graus que exibem a volumetria dos corpos esféricos ou cilíndricos concomitante a uma visão quase frontal dos mesmos. Assim, o desenho Disney incorpora as formas livres/cômicas da caricatura e a tridimensionalidade da escultura, em associação com os elementos cinematográficos.

Os filmes Disney ainda fazem um grande investimento na composição cenográfıca. Embora não seja muito discutida por Thomas e Johnston (1995), a cenografia é uma composição ainda mais sofisticada que a das personagens, mesmo quando relegada a um segundo plano pelo supracitado contraste de linha e cor entre "atores" e fundo. Em Pinóquio, alguns elementos do cenário ganham breve vida na animação, em especial os animatrônicos dos relógios e caixinhas de música de Gepeto, uma galeria à parte de personagens e caricaturas no primeiro ato do filme. E dentre os objetos inanimados, percebemos expressões caricaturais desenhadas ou sulcadas sobre algumas peças que se destacam no entorno. A proliferação de caricaturas nos próprios utensílios, somada aos outros tantos adornos da cenografia, reforça a ambientação lúdica da fábula, em uma copiosidade de figuras paralelas, cores e materiais.

Os backgrounds dispõem de tratamentos detalhados de textura e claro-escuro, sobretudo nos enquadramentos fechados sobre o Grilo Falante, onde vemos os objetos e superfícies em close. A tridimensionalidade continua marcante, na volumetria e dimensão dos penduricalhos e no arranjo dos espaços. Nestes, a profundidade de campo prevalece nos vários contextos de cena e enquadramento: desde os planos aéreos sobre a vila medieval, feitos em planos-sequência bastante complexos, até os planos próximos e fechados com as personagens pequenas. Pinóquio abusa de uma retórica do diverso em que as imagens do entorno oferecem constantes estímulos à nossa visão, vide a configuração dinâmica dos espaços e claros-escuros, as variações de cor e textura dos objetos e a supracitada diversidade de elementos do cenário. Mesmo as "sobras" da imagem apresentam pequenos atrativos por nunca estarem plenamente vazias, e as dinâmicas de espaço e iluminação em particular imbuem todo o quadro de movimento e brilho. 
Robin Allan, em Walt Disney and Europe (1999), identifica uma ambientação germânica na vila medieval de Pinóquio, considerando a decoração dos espaços interiores e a arquitetura urbana. ${ }^{5}$ A vila foi inspirada na Rothenburg ob der Tauber, uma cidade medieval da Bavaria, preservada até hoje para fins turísticos. Allan faz várias associações entre as imagens de Pinóquio e um repertório iconográfico europeu. Os rochedos da Ilha dos Prazeres, por exemplo, são comparados às barreiras de pedra das ilustrações de Gustave Doré para o Inferno de Dante. Além das artes visuais, esse repertório iconográfico faz alusão ao teatro e à literatura: os vilões Cocheiro e Espoleta são associados às personagens grotescas de Charles Dickens, e a raposa João Honesto e o gato Julião ao Volpone de Ben Jonson e a todos os doutores charlatões da Commedia dell'Arte.

Allan discorre sobre a incorporação das imagéticas europeias nas animações Disney, mencionando a influência do desenhista Albert Hurter, nascido na Suiça e contratado pelo estúdio. Especialista na antropomorfização de objetos inanimados, Hurter foi quem introduziu as obras de Wilhelm Busch, Hermann Vogel e Heinrich Kley aos artistas da equipe. 0 ilustrador foi um dos principais responsáveis pelo estilo visual das fábulas Disney, derivado da tradição de gravuras de livros infantis. 0 seu trabalho retomava aspectos do gótico e do grotesco, além das estéticas do simbolismo e do art noveau (Allan, 1999). Nos anos 30 e 40, os animadores Disney também tinham dois grandes ilustradores europeus como referência: Honoré Daumier, admirado pelas paródias visuais e exagerações com linha e massa, e Gustave Doré, pela fusão que seus desenhos faziam entre o melodrama, o fantástico e o macabro (Allan, 1999).

Da Pintura de Leon Battista Alberti (2014) ajuda-nos a entender como os desenhos Disney estruturam-se por meio de uma retórica imagética bastante elaborada. As bibliografias não dizem que os animadores leram Alberti, mas como o tratado pertence a um repertório comum de produção de imagem e como os desenhistas dominavam esse repertório, não é incoerente apontar uma relação entre o desenho Disney e o quadro albertiano. A supracitada retórica do diverso evoca os preceitos albertianos de copiosidade e variedade, que proporcionam satisfação e deleite ao espectador da pintura. Em relação à perspectiva, Alberti sugere o seguinte método: “Começo sempre com as superfícies mais próximas, principalmente com aquelas que estejam igualmente distantes da interseção. Coloco-as na frente das outras, descrevendo suas latitudes e longitudes naqueles paralelos do pavimento" (Alberti, 2014, p. 105-106). Pinóquio apresenta um paralelo a esse modo de figuração nos planos em que a profundidade de campo é sugerida ou posta em evidência por um contraste de escala entre corpos grandes e sombreados no primeiro plano e elementos menores e iluminados no fundo. Em alguns enquadramentos, os elementos da frente são colocados nas laterais da imagem, em consonância com a convenção pictórica de um "ponto de apoio", geralmente identificado como lugar de transição entre o local do espectador e o interior do quadro.

Alberti (2014) também recomenda a emulação de um relevo pelo uso do claro-escuro, desqualificando toda imagem que não sugerir esse volume. Tal princípio é onipresente em Pinóquio, no desenho pictórico dos objetos cenográficos em que modelações da luz e sombra evocam o seu formato e relevo. E embora as caricaturas tenham um estilo gráfico chapado, elas também dispõem de uma composição escultórica sugerida pelas saliências dos contornos. Mas, apesar dos corpos redondos dos "mocinhos" das narrativas, os desenhos Disney ainda trabalham com caricaturas que pressupõem uma deformidade, o que foge às recomendações de Alberti a tudo que não era harmonioso. 0 grotesco é tão presente nos filmes quanto o gracioso, inclusive nas personagens fofas, ainda que o maior exemplo seja os vilões e coadjuvantes cômicas. Não há regras formais para a Disney, apenas o uso de todos os recursos visuais que possam ser interessantes para o espectador.
5:: Identificamos também alguns elementos italianos como as garrafas de vinho envoltas em vime na casa de Gepeto, possivel influência da origem itálica da narrativa principal. 
6:: Poderíamos associar à personagem uma terceira persona de Hollywood: Buster Keaton. As acrobacias do inseto na casa de Gepeto e em outros espaços lembram os malabarismos arriscados do comediante, e a mesma associação pode ser feita com o gato Fígaro, na cena em que este abre a janela de Gepeto.

7:: 0 vilão João Honesto foi dublado por Walter Catlett, outro ator e cantor muito popular dos EUA, que participou de filmes prestigiados como Levada da Breca (Bringing Up Baby, 1938), de Howard Hawks e 0 Galante Mr. Deeds (Mr. Deeds Goes to Town, 1936), de Frank Capra. 0 protagonista Pinóquio também recebeu a voz de uma estrela mirim da época, o ator Dick Jones (Kaufman, 2015).
As animações também referenciam, por exemplo, um repertório imagético estadunidense. Allan (1999) aponta para o topete vistoso do cabelo de Pinóquio, marca registrada dos heróis americanos "caipiras" da literatura e do cinema como Tom Sawyer, Will Rogers e Elvis Presley. 0 boneco remeteria ao próprio Mickey Mouse de Walt Disney, considerando os olhos grandes e amendoados, as covinhas do rosto e o sorriso largo, e as luvas brancas com três marquinhas nas costas (Allan, 1999), também usadas por outras personagens do filme. Outro "americanismo" é a Fada Azul que referenciaria as Vênus Platinadas de Hollywood, em especial a atriz Jean Harlow. A figura etérea das ilustrações europeias é substituída no desenho pela mulher glamourizada e sexualizada do cinema americano, e a estrela dos desejos de onde ela aparece ganha nesse viés uma outra conotação: a estrela dos desejos sexuais (Allan, 1999)

0 principal vínculo com os EUA se daria, no entanto, com o Grilo Falante -no original em inglês, Jiminy Cricket-, um jargão popular dos anos 30, época de produção do filme. Robin Allan considera a personagem uma mistura de W. C. Fields e Charlie Chaplin, o primeiro pela arrogância e autoconsciência do inseto, o segundo pela imagem do herói andarilho. ${ }^{6}$ Para o autor, o Grilo é um elemento contemporâneo inserido na fábula medieval europeia. Embora as referências já não sejam tão evidentes, a personagem usa de vários jargões americanos dos anos 30, incluindo o de um hit musical, Little Man, You've Had a Busy Day. Na cena em que escala os cordões de Pinóquio, por exemplo, o Grilo repete a fala comum dos condutores de elevadores das lojas de departamento (Allan, 1999). A personagem foi dublada por Cliff Edwards, cantor popular dos anos 20 e 30, muito conhecido por suas apresentações com ukulele e aparições em filmes de Hollywood (Kaufman, 2015). ${ }^{7}$

Os repertórios europeus e americanos aparecem não raro simultaneamente. Além dos charlatões da Commedia dell'Arte, Allan associa João Honesto e Julião a personagens da literatura estadunidense como o Duque e o Rei de Huckleberry Finn, de Mark Twain. 0 Grilo também evocaria a tradição europeia de contadores de história, que inclui desde os menestréis medievais até narradores andarilhos como Homero. Segundo Allan, até a vila medieval incorporaria essa imagética dupla, pois a perspectiva acentuada das ruas da cidade e a textura quebradiça dos elementos cênicos remeteriam respectivamente às perspectivas angulosas de Thomas Hart Benton e às paisagens de brinquedo de Grant Wood -dois pintores estadunidenses. A concepção desse cenário veio justamente de Gustaf Tenggren, ilustrador versado tanto na academia vitoriana de pintura e em artistas como Arthur Rackam, Edmund Dulac e Rudolf Bauer quanto na arte comercial americana e nas influências de Hollywood nas artes plásticas (Allan, 1999).

À identificação iconográfica é necessária a reflexão sobre esses repertórios, que mobilizam diversos tipos de imagens. Por exemplo, nos enquadramentos fechados sobre o Grilo, no primeiro ato do filme, o conjunto cenográfico lembra as pinturas de naturezamorta, considerando a disposição e agrupamento dos penduricalhos e o detalhe pictórico das texturas e superfícies. 0 Grilo e as expressões engraçadas de alguns objetos quebram com a solenidade formal e técnica da natureza-morta, o que também encontra ecos na história da pintura se lembrarmos de quadros como A raia (La raie, 1728) de Chardin. Neste, o gato invadindo a mesa (talvez indo pegar algumas ostras) e a raia jocosa pendurada na parede acrescentam um tom anedótico à natureza-morta, para não mencionar o grotesco da raia com as tripas de fora.

Ainda que harmonize com a cenografia em termos de proporção e cor, o Grilo destoa do conjunto por ser uma caricatura. 0 desenho gráfico e levemente cômico da personagem contrasta com a figuração pictórica da natureza-morta, e o carisma e maior expressividade do inseto distinguem-no até das caricaturas sulcadas nos objetos, 
ainda destituídas de movimento e "formalizadas" pelo purismo de textura e composição. A cenografia de fundo europeu é ocupada, portanto pela caricatura, e especificamente pela caricatura americana, dada a forte referência no desenho da personagem a um estilo gráfico estadunidense (os desenhos de W. W. Denslow) e a tipos e figuras como o "novo-rico" americano. Robin Allan (1999) faz uma comparação entre o Grilo Falante e Gepeto. 0 carpinteiro, um velho pedante refugiado em sua loja, representaria o mundo europeu em toda sua graça, nostalgia e pitoresco, ao passo que o Grilo seria o agente americano que invade esse mundo, apropriando-se dos objetos para sua bel diversão e necessidade. Podemos acrescentar que a personagem tem uma atitude muito irreverente, considerando a sem-cerimônia com que se aquece na lareira ou com que converte um serrote num trampolim e um violino em corda-bamba, ao modo de um brinquedo benjaminiano.

Entretanto, Allan restringe-se à narrativa e não explora a tensão das iconografias no plano da imagem. A apropriação destes repertórios visuais ressignifica as imagens e agrega valores simbólicos ao filme. Se na cidade medieval, por exemplo, o perigo residia nos espaços privados e não públicos, em Pinóquio, o espaço interno doméstico, simbolizado pela loja de Gepeto, é um lugar de aconchego e segurança que protege as personagens das ameaças do mundo de fora, conforme a ideologia burguesa sobre os espaços urbanos. A composição imagética do filme evoca constantemente esse enclausuramento com os supracitados corpos sombreados do primeiro plano, vistos em escala ampliada. Além de emularem a perspectiva, eles confinam as personagens no interior do quadro, a despeito das aberturas das laterais que antecipam as associações da montagem. A isso se soma os vários enquadramentos em que um foco de luz aparece em um ponto específico do espaço e cercado pelas sombras. Outro exemplo é o plano de abertura do filme em que Pinóquio, um romance moderno do final do século XIX, é representado com capa de couro ao estilo medieval. Ele é visto ao lado de outros romances modernos - Alice no País das Maravilhas e Peter Panencadernados da mesma maneira. 0 livro medieval dá outro estatuto às histórias modernas, sobretudo se considerarmos que os encadernados suntuosos da Idade Média eram livros religiosos.

A relação com o repertório europeu de imagem não se reduz ao complexo de inferioridade de uma arte americana ou a uma estética hollywoodiana kitsch. Ela pode ser interpretada em termos de uma retórica imagética com a qual os filmes Disney ganham duas cartas na manga. A caricatura exerce um forte apelo para com um público familiarizado com tirinhas de jornais, livros ilustrados e cartoons de animação. Ela conversa com um repertório popular de imagem e garante a comunicação com um escopo amplo de espectadores, unindo-se a outras iconografias do cinema e mesmo do teatro. ${ }^{8}$ Contudo, a mesma caricatura é aprimorada por um desenho que preza pela complexidade das formas. Não se trata de qualquer cartoon, mas de uma composição mais elaborada que dialoga com um cânone de imagem, e o mesmo se dá com o tratamento pictórico cenográfico, não raro quase mais chamativo que as personagens da animação. 0 repertório da história da arte acopla-se então à iconografia popular como um argumento de autoridade, pois eleva a animação Disney ao patamar de criação artística, no sentido convencional do termo.

\section{Narrativa, Personalidade e Encenação}

Como animadores da Disney, Frank Thomas e Ollie Johnston obviamente elegem o desenho do estúdio como parâmetro para todo o cinema de animação, no sentido de estabelecer o que pode ou não ser animado e como isso deve ser feito. Os cartoons anteriores a Disney seriam menos desenvolvidos por não apresentarem personagens envolventes e individualizadas ou
8:: Segundo Thomas e Johnston, o teatro vaudeville foi outra grande inspiração para as animações. 


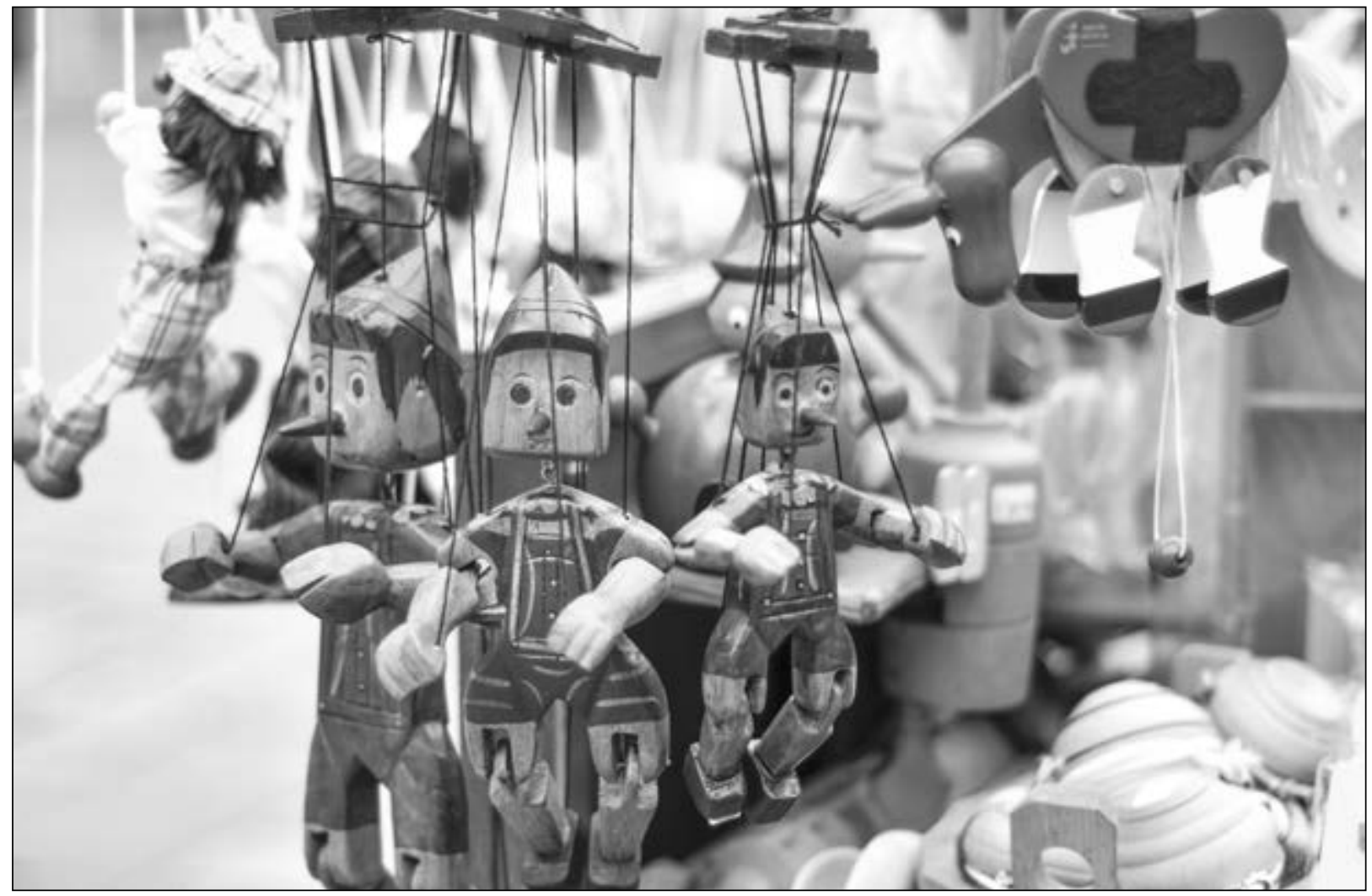

Foto: Pixabay

narrativas mais bem elaboradas, ainda que os autores reconheçam que alguns trabalhos tenham chegado perto disso -por exemplo, Gertie, the Dinosaur, animação pioneira de 1914 de Winsor McCay, a série Out of the Inkwell de Max Fleischer e os filmes do Gato Félix, de Otto Messmer.

Em Before Mickey: The Animated Film, 1898-1928, Donald Crafton (1993) também orienta sua retrospectiva no desenvolvimento da chamada animação de personalidade nos cartoons estadunidenses (ou seja, a animação de personagens individualizadas, inseridas numa narrativa). Entretanto, para Crafton ela não é exclusiva da Disney, pois o único diferencial do estúdio teria sido o aprimoramento técnico da animação e o maior planejamento dos desenhos e encenações. 0 que nos interessa, contudo, é a história dos primeiros desenhos animados. Segundo Crafton, as primeiras animações não derivaram das tirinhas de jornal ou histórias em quadrinhos, como comumente associado, mas sim de uma atração popular conhecida como lightning sketches. Nesta, um ilustrador fazia sobre um quadro negro um desenho atrás do outro bem rapidamente e a sucessão de imagens criava a ilusão de figuras em contínua metamorfose. Os primeiros cartoons associavam-se a esse número, especialmente quando mostravam junto aos desenhos os artistas ou a mão que os criavam. Os filmes distinguiam-se, no entanto, pela "real" movimentação das imagens e com o tempo estas se tornaram as atrações exclusivas do curta-metragem. Crafton considera o francês Emile Cohl o primeiro grande animador. Em seu icônico filme Fantasmagorie, de 1908, as linhas do desenho transformam-se espontaneamente em novas formas e figuras, em um movimento único e contínuo que antecipa o fluxo de consciência surrealista.

Foi só mais à frente que os desenhos animados começaram a utilizar figuras e narrativas dos quadrinhos, sobretudo nos EUA, nas animações pioneiras de Winsor McCay que transpôs personagens de suas próprias tirinhas para as animações. Mas até McCay seguia a tradição dos lightning sketches ao se colocar na frente dos desenhos como um mestre de cerimônias, e Gertie, The Dinosaur exibe a interação entre esse artista/homem de espetáculo e a figura dócil e desajeitada do cartoon. As animações consistiam, portanto, em números de mágica e circo e não construções narrativas, o homem com o giz de cera substituindo o mágico com a cartola. Os desenhos alinhavam-se ainda à tradição dos filmes ilusionistas cuja maior referência era George Meliés, e foram eles que revitalizaram o gênero quando o público já perdia o interesse pelo tema (Crafton, 1993). 
Foi Hollywood quem trouxe à animação a questão da narrativa, e em especial os estúdios Disney. Os desenhos do Gato Félix e do palhaço Koko ainda eram formados por uma série de gags ou números cômicos, desprovidos de grande propósito narrativo, ainda que os protagonistas fossem de fato personagens distintas e personalizadas. Foram sobretudo os desenhos Disney que começaram a desenvolver narrativas de começo, meio e fim, com os filmes de Mickey Mouse e as Silly Symphonies dos anos 30, que preparam terreno para os primeiros longas-metragens. Não é incoerente considerar Walt Disney o Griffith dos desenhos animados, uma vez que foi ele quem consolidou um cinema narrativo de animação, nos moldes da tradição hollywoodiana. Inclusive, consolidou-se com o tempo a ideia de que as animações anteriores a Disney eram primitivas e irregulares, assim como os filmes anteriores a Griffith. Estudos como os de Crafton (1993) mostram quão preconceituosa essa afırmação é. As linhas metamórficas de Emile Cohl, o desenho tridimensional do dinossauro Gertie e do dragão-carruagem de Little Nemo de Winsor McCay, o complexo uso da rotoscopia em Out of the Inkwell, os expressionismos e surrealismos de Felix, the Cat: todos são exemplos de uma estética elaborada em seus próprios méritos, e isso porque não mencionamos animações europeias como o teatro de sombras de Lotte Reiniger e os insetos em stop-motion de Ladislaw Starevich.

Contudo, não podemos afirmar que a animação Disney é somente uma construção de narrativa. Pinóquio nos dá muitos exemplos do contrário: as gags com os relógios e caixinhas de música, os números musicais com o Grilo Falante, a comédia-pastelão de João Honesto e Julião, as acrobacias do Grilo e do gato Fígaro, as coreografias do teatro de marionetes, as atrações monumentais da Ilha dos Prazeres, a multitude colorida de criaturas marinhas e os percursos da câmera sobre a cenografia. Todos esses números abstraem-se da narrativa principal, sustentando-se como sequências autônomas no filme. De nada serve à história a dança do Grilo nos cordões do violino ou a peixe Cléo flertando com o gato Fígaro, mas são essas cenas que definem o tom cômico e lúdico do longa-metragem.

As caricaturas do filme são tão ou mais importantes que a narrativa. É a força plástica e cômica dos desenhos que determina a sua calorosa recepção pelo público, para além do papel ou função das personagens na história. Se a plateia cai de amores pelo gato Fígaro ou treme de pavor do Cocheiro isso se deve ao respectivo carisma e grotesco das caricaturas, e se as personagens não tivessem esse apelo imagético, talvez não provocassem o mesmo envolvimento por parte dos espectadores. Em Pinóquio, a caracterização das personagens é construída pelos desenhos mais o contraste entre os mesmos, em consonância com um princípio de fisiognomia, tão presente na tradição da caricatura. Um bom exemplo são as personalizações do inocente Pinóquio e do vadio Espoleta. Pinóquio é um menino de bochechas infladas e coradas, sorrisos largos e olhos azuis amendoados com pupilas pretas. Já Espoleta é um moleque de mãos enormes, quase do tamanho da cabeça, orelhas de abano e olhos tão estreitos que mal destacam suas pupilas. Ele também tem um nariz arrebitado semelhante a um focinho e um sorriso dentuço que lembra o de um esquilo.

A construção de personagem também envolve transformações na própria fisionomia, como no final da sequência da taberna em que o Cocheiro revela o seu caráter diabólico em uma metamorfose gráfica e cromática. Se no começo os olhos, nariz e boca da personagem concentram-se na parte central de seu rosto, deixando um excesso de pele rosada nas laterais da cabeça (o que prenuncia uma introspecção ameaçadora), no clímax os olhos tornam-se maiores e lustrosos e a boca abre um sorriso gigante que exibe as duas fileiras de dentes e até parte das gengivas. 0 conjunto "preenche” a extensão do rosto e este ganha nuances de sombra e um aspecto avermelhado. A pele rosada $e$ as orelhas e cabelos arrepiados chegam a lembrar a 
figura de um demônio. Os detalhes do figurino são igualmente importantes na caracterização. Os rasgos no dedo mindinho das luvas e os remendos das capas e cartolas denunciam a penúria de João Honesto e Julião, por mais que estes tentem simular uma falsa nobreza. As barbatanas de Cléo, finas como um véu de seda, lembram o leque das aristocratas francesas, especialmente quando a peixinha as projeta na frente do rosto. As mangas largas de Gepeto sugerem a sua pobreza, assim como as calças curtas, quase na altura dos joelhos, embora as mangas também sirvam para harmonizarem com a papada do rosto.

Até as massas corpóreas definem as personagens. Em Pinóquio, os vilões são figuras corpulentas e pesadas que intimidam os mocinhos pequenos e/ou magricelas. 0 exemplo máximo disso é a baleia Monstro que é praticamente reduzida a uma massa negra gigante, de pouca expressividade. A raposa e o gato seriam exceções, mas estas representam mais um gracejo cômico do que um antagonismo de fato. Ainda que maliciosos, João Honesto e Julião são bastante tolos e deixam-se enganar facilmente pelos outros vilões. São os antagonistas peso pesados como Stromboli, o Cocheiro e Monstro que oferecem uma ameaça de morte.

Não por acaso, um dos doze princípios de animação de The Illusion of Life é o chamado princípio do apelo (appeal) que preconiza uma qualidade de design que torne o desenho mais interessante ou agradável ao espectador (um preceito compatível com o ideal albertiano de satisfação aos observadores do quadro). Os animadores Disney recomendam que o design das personagens e demais composições visualize o essencial, como no desenho objetivo da caricatura, embora concomitante a um arranjo dinâmico das formas e proporções, sem que o desenho seja muito simplificado. Não é errado pensar a animação como um veículo de sentimentos e emoções, como colocam os autores do livro ao associarem-na a uma dramaturgia. Mas esse pathos deve ser pensado em relação à imagem, pois são os acentos e deformações da caricatura que constroem o drama ou o humor de uma cena, junto aos recursos cromáticos e cenográficos. Isso se aplica inclusive a outros gêneros fílmicos além da animação ou da comédia. 0 pathos visual proporcionado pelo exagero, tão presente na caricatura, pode ser associado até ao melodrama.

A encenação das personagens (seus gestos e ações) também é um fator muito importante, e a mise-en-scène de Pinóquio é bastante complexa em termos de caricatura do movimento, por exemplo, a cena em que Fígaro pula para a cama de Gepeto, evocando simultaneamente as ações de um gato e de um menino mal-humorado. As personagens da animação usam o corpo de maneira muito expressiva. Na cena em que o Grilo Falante diz a Pinóquio que ele não deve ir ao teatro, o inseto faz uma mímica para cada frase que pronuncia: "diga-lhe que agradece" -levanta a cartola - "sente muito" -faz uma reverência, etc. 0 Grilo não precisaria fazer todos esses gestos já que escutamos muito bem as suas palavras. A performance paralela da personagem remete à encenação corporal do cinema silencioso, de grande força imagética, e aos esquemas de repetição retórica que nos ajudam não só a entender a mensagem, mas a memorizá-la. A gestualidade corporal não se limita à caracterização das personagens: ela instaura o humor. A comédia é construída, por exemplo, no contraste entre os gestos afetados da raposa João Honesto e os movimentos ébrios do gato Julião, que repete as ações do comparsa com certo atraso e de maneira abobalhada, lembrando o gato do livro de Carlo Collodi que sempre repete as últimas palavras da raposa.

0 número performático não se prende à narrativa e muito menos deve seu valor ao lugar ou função na história. Pinóquio inclusive pode ser considerado mais uma compilação de performances do que de episódios narrativos, pois as mímicas e coreografias tornam-se não raro os objetivos últimos ou principais das sequências, sendo uma atração ou espetáculo à parte no filme. Uma piada comum sobre as animações Disney é que os musicais possuem muito mais espaço que os enredos da sinopse, o que não deixa 
de ser verdade considerando que o desenvolvimento da narrativa é várias vezes preterido pelas danças, músicas e gracejos, sobretudo nos filmes mais antigos do estúdio. Mas é essa a principal qualidade das animações e não o seu defeito, dado que as narrativas Disney são simplificadas e conservadoras. Os musicais e outras atrações proporcionadas pelas caricaturas, mise-en-scène e cenografia garantem que os filmes não se subsumam à história problemática, e até as personagens das narrativas, teoricamente comprometidas com o enredo, ultrapassam-nas com muita facilidade, vide o Grilo Falante que transita continuamente para dentro e para fora da história.

Um exemplo elucidativo é o longa-metragem Mogli-O Menino Lobo (The Jungle Book)-, lançado em 1967 e cultuado até hoje pela qualidade dos desenhos e coreografias mais a antropomorfızação cômica dos bichos (por exemplo, os abutres-Beatles do pântano e o tigre Shere Khan à George Sanders). 0 ponto alto do filme não é a narrativa de teor exótico e colonialista, mas a dança de Mogli e Baloo, o baile dos orangotangos, o contorcionismo da cobra Kaa e as demais caricaturas e números performáticos das personagens. E se Mogli não possui a mesma força de Pinóquio é porque este, em acréscimo às animações e personagens, concede maior protagonismo à sua cenografia, o que dá ao filme outras nuances de fantasia e drama, derivadas da força iconográfica da paisagem e da natureza-morta. Nos anos 40, várias produções do estúdio apresentaram breves experimentações de imagem, performance e música, como o icônico Fantasia (1940) e os subestimados Música Maestro! (Make Mine Music, 1946) e Tempo de Melodia (Melody Time, 1948). 0 clássico Alice no País das Maravilhas (Alice in Wonderland) de 1951 também usa a narrativa nonsense de Lewis Carrol como pretexto para abusar das possibilidades da animação no que se refere à caricatura, composição e cor, chegando a antecipar uma estética psicodélica. Nos outros longas do estúdio essa experimentação também aparece, embora limitada a sequências específicas, e não por acaso as melhores dos filmes.
Isso não significa que a ideologia das narrativas se torne irrelevante. A figuração -e entendendo por figuração as caricaturas e performances da animação- também pode trazer consigo os valores conservadores do texto. No filme Dumbo (1941) temos o exemplo da sequência musical "When I See An Elephant Fly”, em que um bando de corvos incorpora estereótipos racistas da época, potencializados pelo número de jazz da música e pelo sotaque carregado da dublagem original. A coreografia das personagens, entretanto, é brilhantemente executada em termos de animação de movimento, e embora seja inegável o valor de técnica e encenação que a performance agrega à sequência, isso não anula o racismo do filme e chega até a deixá-lo mais enfático. A figuração não é inseparável da ideologia, mas também não se submete completamente a ela. E ao mesmo tempo em que a imagem e a performance fortalecem o discurso da narrativa, pelo apelo estético ou dramatúrgico agregado, elas igualmente possuem a perversa capacidade de subverter ou trair esse mesmo discurso, permitindo que o filme inquietantemente nos agrade apesar do conteúdo extremamente pejorativo ou conservador da história.

Atuais pensadores da imagem como Georges Didi-Huberman (2008) e Hans Belting (2014) falam, embora em caminhos quase diametralmente opostos, dessa "coringa" potencialidade da imagem em abalar discursos ou conhecimentos prévios associados a ela. Didi-Huberman, a partir do legado de Aby Warburg, discorre sobre a experiência de abertura causada por imagens que desapossam seu espectador, pondo em frangalhos tudo que este acreditava dominar sobre elas (Didi-Huberman, 2008). Já Belting defende que o fenômeno da imagem requer não apenas a forma e seu suporte (os quais, coisas distintas) mas o corpo de um espectador. As diferentes apropriações possíveis da imagem no corpo, memória e percepção deste espectador desestabilizam uma relação de causa e efeito entre as intenções originais do artista ou do contexto da obra e a sobrevida da mesma naqueles que a recebem (Belting, 2014). Embora os desenhos Disney não sejam contemplados por esses autores, eles 
demonstram, como exemplificado no começo do ensaio, a perturbadora contradição possível entre imagem e narrativa. Junto a outras animações dos primeiros anos do estúdio, Pinóquio demonstra muito bem como o apelo da imagem e da encenação pode enfraquecer ou desestabilizar o discurso ideológico, seguindo um paradoxo já conhecido na filosofia em que um espetáculo é criado para se falar mal do próprio espetáculo (no caso, o boneco que diminui o teatro em um filme que exala performance em todos os seus poros). Inclusive, é o desconforto causado pela sofisticação técnica da imagem concomitante ao discurso conservador da narrativa que torna os desenhos Disney tão interessantes e mesmo necessários para uma discussão aprofundada sobre o que é de fato a indústria cultural e o porquê de ela manter-se tão forte mesmo depois de todas as reprovações feitas à dita sociedade do espetáculo.

Na obra visual não é apenas o que está sendo contado que importa, mas como isso é apresentado. Por exemplo, quando Pinóquio vai para o teatro de Stromboli, é evidente que ele cairá numa armadilha, e o espectador é cativado não tanto pelos acontecimentos dos "próximos capítulos", mas pela maneira com que esse suspense é desenvolvido. 0 que nos comove ou surpreende é a imagem do menino trancafiado na gaiola ao lado de várias marionetes dependuradas no teto pelo pescoço, como prisioneiros enforcados, e isso sem mencionar o efeito dramático da luz do relâmpago que se propaga no quarto escuro. Sobre essa construção de imagem, é curioso que Pinóquio, além de caricaturas carismáticas, lance mão de várias imagens de pesadelo e grotesco. Walter Benjamin (1985) já dizia que o cinema dá expressão às psicoses da sociedade moderna e industrial, e uma das suas referências era os desenhos de Mickey. 0 feio e o repulsivo aparentam ser outra estratégia de atração do público, especialmente nos primeiros filmes do estúdio em que o macabro foi muito recorrente, dos esqueletos dançarinos de $A$ Dança dos Esqueletos (The
Skeleton Dance, 1929) ao demônio na montanha de Fantasia. Bebendo do cinema expressionista alemão e do repertório gráfico de artistas como Gustave Doré, o grotesco dos desenhos (gradativamente diluído ao longo dos anos nos filmes do estúdio) é um elemento que frequentemente abala o tom agridoce e idealizado das narrativas.

No grupo dos The Nine Old Men, ${ }^{9}$ o animador Ward Kimball era considerado o "iconoclasta da equipe". Dotado de um forte senso de paródia, Kimball interessava-se mais pelas gags e coreografias do que pela dramaturgia da história. Foi ele quem dirigiu a sequência musical de The Three Cabaleros (no Brasil, Você Já Foi à Bahia?, de 1944) onde Panchito, Pato Donald e Zé Carioca dançam a música-título. Embora o desenho sólido seja onipresente na animação, ele é subvertido várias vezes em metamorfoses de forma e cor, lembrando os cartoons antigos inspirados pelos lightning sketches. Em Pinóquio, Kimball foi responsável, não por acaso, pela animação do Grilo Falante, a personagem mais irreverente do filme, e nos demais longas-metragens o animador sempre deu preferência a coadjuvantes cômicos que lhe garantissem certa liberdade, como os ratos Jaq e Tatá e o gato Lúcifer de Cinderela (Cinderella, 1950) e o gato de Chesire de Alice no Pais das Maravilhas (Thomas e Johnston, 1995). O humor básico de Kimball originava-se dos desenhos em si e não somente das encenações.

Como vimos ao longo do texto, as produções do estúdio Disney possuem um farto domínio de imagem e sustentam-se em última instância por composições visuais de grande sofisticação formal e apelo iconográfico. Não obstante, na tradição ocidental, profundamente iconoclasta, não há maneira melhor de barganhar as imagens do que as oferecendo como narrativas. Mas supor que as histórias determinam o que são os filmes Disney é não entender porque as animações ainda têm uma plateia tão cativa, e não apenas entre as crianças. 


\section{Referências}

Allan, R. (1999). Walt Disney and Europe: European Influences on the Animated Feature Films of Walt Disney. Eastleigh, Australia: John Libbey \& Co.

Alberti, L. B. (2014). Da Pintura (A. Da Silveira Mendonça, Trad.). Campinas, Brasil: Editora da Universidade Estadual de Campinas.

Belting, H. (2014). Antropologia da Imagem: Para uma ciência da imagem (A. Morão, Trad.). Lisboa, Portugal: KKYM.

Benjamin, W. (1985). A obra de arte na era de sua reprodutibilidade técnica. Magia e Técnica, Arte e Política: ensaios sobre literatura e história da cultura (S. P. Rouanet, Trad.). São Paulo, Brasil: Brasiliense.

Box Office Mojo. (2018). Yearly Box Office Results - Box Office Mojo. Disponivel em https://www.boxofficemojo.com/yearly/?view2=worldwidectp $=$.htm

Crafton, D. (1993). Before Mickey: Animated Film, 1898-1928. Chicago, IL: The University of Chicago Press.

Didi-Huberman, G. (2008). La condition des images. Disponivel em https://goo.gl/N2bxsY

Kaufman, J. B. (2015). Pinocchio: The Making of Disney Epic. San Francisco, CA: Walt Disney Family Foundation Press.

Mitchell, W. J. T. (1987). Iconology: Image, Text, Ideology. Chicago, IL: The University of Chicago Press.

Morin, E. (2011). Cultura de Massas no Século XX: Neurose (Volume 1). São Paulo, Brasil: Editora Forense Universitária.

Rancière, J. (2012). 0 espectador emancipado (I. C. Benedetti, Trad.). São Paulo, Brasil: Editora WMF Martins Fontes.

Thomas, F., e Johnston, O. (1995). The Illusion of Life. New York, NY: Disney Editions.

\section{Filmes}

Bozzetto, B. (Producer), \& Bozzeto, B. (Director). (1978). Allegro non troppo [Motion Picture]. Italia: Bruno Bozzetto Film; Ministero del Turismo e dello Spettacolo.

Capra, F. (Producer), \&t Capra, F. (Director). (1936). Mr. Deeds Goes to Town [Motion Picture]. United States: Columbia Pictures Companies.

Disney, W. (Producer), \& Disney, W. (Director). (1929). The Skeleton Dance [Motion Picture]. United States: Walt Disney Productions.
Disney, W. (Producer); Et Ferguson, N. (Director). (1944). The Three Caballeros [Motion Picture]. United States: Walt Disney Productions.

Disney, W. (Producer), \&t Geronimi, C.; Jackson, W.; Kinney, J.; Luske, H. (Directors). (1948). Melody Time [Motion Picture). United States: Walt Disney Productions.

Disney, W. (Producer); \&t Geronimi, C.; Jackson, W; Luske, H. (Directors). (1951). Alice in Wonderland [Motion Picture). United States: Walt Disney Productions.

Disney, W. (Producer); \&t Geronimi, C.; Jackson, W; Luske, H. (Directors). (1950). Cinderella [Motion Picture). United States: Walt Disney Productions.

Disney, W. (Producer), \&t Hand, D. (Director). (1937). Snow White and the Seven Dwarfs [Motion Picture]. United States: Walt Disney Productions.

Disney, W. (Producer), \&t Luske, H.; Sharpsteen, B. (Directors). (1940). Pinocchio [Motion Picture]. United States: Walt Disney Productions.

Disney, W. (Producer), \& Reitherman, W. (Director). (1967). The Jungle Book [Motion Picture]. United States: Walt Disney Productions.

Disney, W. (Producer); \& Sharpsteen, B (Producer). (1941). Dumbo [Motion Picture]. United States: Walt Disney Productions.

Disney, W.; Sharpsteen, B. (Producer), \&t Algar, J.; Armstrong, S.; Beebe Jr.; F.; Ferguson, N.; Hand, D.; Handley, J.; Hee, T.; Jackson, W.; Luske, H.; Roberts, B.; Satterfield, P.; Sharpsteen, B. (Directors). (1940). Fantasia [Motion Picture]. United States: Walt Disney Productions.

Grant, J. (Producer), \&t Cormack, R.; Geronimi, C.; Kinney, J.; Luske, H.; Meador, J. (Directors). (1946). Make Mine Music [Motion Picture]. United States: Walt Disney Productions.

Hawks, H.; Reid, C. (Producers), \& Hawks. H. (Director). (1938). Bringing Up Baby [Motion Picture]. United States: RKO Radio Pictures.

McCay, W. (Producer), \&t McCay, W. (Director). (1914). Gertie the Dinosaur [Motion Picture]. United States: McCay; Vitagraph Company of America.

McCay, W. (Producer), \&t McCay, W.; Blackton, S. (Directors). (1911). Winsor McCay, the Famous Cartoonist of the N.Y. Herald and His Moving Comics (Little Nemo) [Motion Picture]. United States: Vitagraph Company of America. 